Available online at $\quad$ http://www.jfas.info

\title{
PROBLEMS OF GEOINFORMATION SYSTEM DEVELOPMENT AND INTRODUCTION IN GEOGRAPHICAL EDUCATION
}

\author{
R. A. Ulengov, N. K. Gabdrakhmanov* \\ Kazan Federal University, Russian Federation, Republic of Tatarstan, 18 Kremlyovskaya St. \\ Kazan 420008
}

Published online: 08 August 2017

\begin{abstract}
The transition to the use of new information technology means is a characteristic feature of the modern general education and higher school. The programs of informatization are being implemented and the means of education informatization are being developed in the educational process of the educational institutions of Tatarstan within the framework of the priority national project "Education".

Modern educational standards also pay special attention to the need of competence development in the use of information and communication technologies, including the formation and the development of competence in the use of information and communication technologies at the public level, including the possession of information and communication technologies, the search, the design and transfer. Similarly, the requirements for the subject results of an in-depth geography course mastering should reflect the ability to use geoinformation systems [8].

Taking into account the expanding possibilities of computers, the growth of information cognitive activity of students and the persons just interested in geography and ecology, the task of a qualitatively new educational GIS creation combining data from toponymy, cartography and geography is a relevant one. The educational process at educational institutions requires the creation of teaching aids that will simplify the learning process. Within geography, which is common both at schools and at universities, geoinformation systems should become such a unique teaching tool.
\end{abstract}

Author Correspondence, e-mail: ulengovr@mail.ru

doi: http://dx.doi.org/10.4314/jfas.v9i2s.74 
The use of GIS will improve the visibility, the perception of material, the variability of the cartographic image, but it does not contain a learning component.

Key words: education, geographic information systems, geography programs.

\section{INTRODUCTION}

The purpose of the study is to analyze the application of geographic information systems in the teaching of geography and to discuss the possibilities of deeper introduction of GIS in the geographic education of Tatarstan.

The concept of Russian education modernization denotes the need for the orientation of education on the mastering of a certain amount of knowledge by students, on the development of his personality, cognitive and creative abilities. A general education school should not only form an integral system of universal knowledge and skills, but also an independent activity and personal responsibility of students [6].

The new educational standard indicates the development of information and communication competence (IC competence) for a graduate of a general education school by the use of various digital models in the educational process [1]. The general education school should form not only an integral system of universal knowledge, and skills, but also an independent activity and personal responsibility of students (i.e., key competencies). [10]

GIS will improve the material visibility and perception, but it does not always contain a learning component. There is the need to create special educational systems for the educational process in geography within the educational community, which would combine the teaching, information and cartographic components. Taking into account that the information deficit has developed in modern geography, especially in certain regions, in particular for toponymy and cartography, the development of a system for an accelerated selfstudy of the nomenclature in geography will create presumably a positive trend in the acquisition of this product at the domestic market. At the same time, the base of consumers will not be limited only to students and teachers, but it will also expand, including school teachers, where the nomenclature is used in special courses and at the lessons of physical geography for the grades 7-8. At the moment, the nomenclature is mastered only by several people in the school environment.

Study methods. The analysis of literary sources, normative documents, comparative analysis 


\section{RESULTS}

The popularity of GIS technologies in Russian geographical education increases. GIS are used especially widely in the analysis of spatial processes and phenomena: in geography, geology, ecology, biology, etc. [2]. But the attempts of their implementation are difficult. If the graduates of recent years study the course "Geoinformation technologies in school geography and ecology" within the framework of the university program, then the graduates of previous years (the base of geography teachers) did not take this course. There is no program aimed at geoinformation literacy increase within the training of geography teachers in the republic. Thus, self-education processes prevail in the development of GIS. The possibilities of school geoinformation systems are unlimited, and their use will allow a primary school teacher to organize the educational process in accordance with the requirements of CE FSES [5]. The problem of geoinformation technology introduction is also relevant in other countries.

Tim T. Favier and Joop A. van der Schee identify the lack of clear standards and characteristics for an optimal use and the development of geographic projects, as well as the lack of attention to the issues related to their teaching, as the problems of geoinformation system introduction in the Netherlands [11]. In Northern Cyprus, GIS is rarely used in secondary schools during geography classes. The introduction of GIS into the curriculum at technical and pedagogical faculties, where students are taught how to use them in geography lessons was a positive step for universities. Mustafa G. Korucu believes that the Ministry of Education of Northern Cyprus should support teachers and the teaching of geoinformation systems should be a mandatory discipline of a university program [12]. In Malaysia, GIS is also poorly implemented in the geography of secondary schools due to the lack of necessary equipment and poor ICT development. The data of researchers from Australia showed that almost $90 \%$ of geography teachers in Malaysia understand the importance of GIS use in geography teaching, some have already begun to use GIS technology in their work. It was revealed that the main problems preventing teachers from GIS use are the lack of software for GIS and the incompatibility of teaching methods with the current curriculum for geography [3]. Nevertheless, there is also a personnel problem - the need to increase the number of experts in the field of computer technologies, which could repair damaged equipment.

The introduction of GIS technologies in Tatarstan also causes many problems. In addition to the low motivation of geography teachers (especially the older generation), it is necessary to take into account that the school GIS was created on the basis of a professional program. Despite the existence of a fairly detailed guide to the study, it is for the teachers with a very 
high workload at school, difficult for independent mastering [7]. The software shell allows you to create and edit digital vector and raster maps, to perform the measurements and the calculations of distances and areas, to design 3D models of different territories, to work with digital space images and apply them on maps. It also has the tools for the operation of statistical data [8].

The shell toolkit allows you to read a digital map, getting more information about natural, technogenic, social objects as compared to conventional paper maps and atlases. It is possible to overlay different thematic maps and create your own digital map, incl. the use of a GPS receiver. The developed tools for digital map editing allow you to apply various geographic information to a map, using both standard and conventional signs created by students.

Basically, geography teachers use school GIS in demonstration mode during the learning of new material or the repeating and the summarizing of the studied one. This is the case if a teacher has only one computer in his office with a projector, a screen or an interactive whiteboard. But the main mode of school GIS use, which makes it possible to realize the activity paradigm of CE FSES, is the mode of direct work of students with it at a computer class under the guidance of a teacher. GIS allows students and teachers to perform such activities as interactive analysis and the filling in of maps, the creation of their own maps and terrain plans, the work with different types of contour maps, the creation of their own individual descriptions of geographical objects and historical events based on the analysis of information objects on maps.

For a wider introduction of information technologies into the educational process, we propose the development of a special system based on GIS and toponymy in the format of a digital package with a self-learning system and the repetition of the material with a built-in information toponymic database. In this format, a geo-information training system allows to develop a uniform toponymic minimum format for the experts in the field of geography and will improve the productivity of self-learning process. The increase of the program value, as a literary source, allows to create a toponymic dictionary which will be attached to the cartographic data. The name "TopoMaps" refers to the trend towards a two-sided orientation of the system - the removing of information from a topographic map and the projecting of objects onto a physical training map. In order to increase the consumer demand for this product, it is proposed to create the versions in the state and English languages for all categories of educational institutions. 


\section{DISCUSSION}

Earlier, there were no ideas in Tatarstan about the creation of special hybrid programs linking different branches of science through the synthesis of different kinds of tasks and the forms of training. Such a mixture of components from different sciences makes it possible to develop a software product that would help achieve the goal of learning process through a training system and a scientific reference block of information. This is the essence of innovation and novelty called the "geoinformation learning system" (GILS). GILS development requires to carry out a number of applied works on the creation of an acceptable software environment. The use of standard programming techniques even in the Arc GIS environment [1] will not give a desired result. Therefore, it is necessary to conduct in-depth development of a software application. Internships for young scientists are established in order to achieve this goal. The self-control mode, in which several algorithms are mixed - random interrogation, the recognition of objects by buffer zones, and the acceptance of correct answers is especially complicated. The task is complicated by the fact that the thing is not just about programming commands, but about the introduction of entire spatial objects, some of which perform the functions of key values. Therefore, this work, for all practical purposes, has a research character and requires the use of qualified personnel.

The content of the system is linked with the toponymy of physical geography. The relevance of this topic is in the absence of a single toponymic collection in a book form for universities and institutes, and a weak cartographic base - orographic maps of Kazakhstan are found in the form of multi-sheet topographic images. Image data does not give a holistic perception and, moreover, it is difficult to superimpose them on a single physical map. Cartographic and information sources on toponymy are not common at schools [2]. In this project it is proposed to create a product containing cartographic (visual) and information sources.

Another similar analogue was found in Belarus, where the team of cartographers was implementing the project to create an educational GIS on the history of the republic [4]. The principal differences in the proposed project are represented by the thematic focus - in the case of the GIS system the bias goes to the history of the Fatherland and historical geography for the history of Belarus (within the university program). GIS-system has only a viewing mode with a special interface for data management. GILS "TopoMaps" differs, first of all, by the availability of teaching functions. The thematic difference of these projects illustrates only a general orientation.

Other works of the Near Abroad are the electronic versions of atlases and even contour maps. In recent years, the practice of geography teaching at a secondary school has been used to 
simulate new interactive maps using the GIS "Live Geography" developed by CJSC "Design Bureau" Panorama" [5]. The school geoinformation system includes a software geoinformation shell (GIS shell) with the tools to work with geographical information, digital geographic maps of the world and Russia and a set of space images. The program provides the opportunity to create your own maps and terrain plans, to work with different types of contour maps, to create your own individual descriptions of geographical objects based on the analysis of existing information objects in the system, to process and perform spatial analysis of statistical materials.

In the spring of 2009 , the company " $1 \mathrm{C}$ " released a new software product - Interactive maps with automatically verified tasks - a modern effective tool for the work in a classroom and the self-preparation of students of 6-10 grades for geography classes. There are 70 maps, each of which is presented in two versions: a control task; an exercise task with a hint. Technical features: the transfer of evaluation to the electronic journal of the educational process organization and support "1C: Education 4. School 2.0". 1C: The designer of interactive maps allows a teacher-methodologist to create maps, charts and tasks saturated with interactive objects independently, without the help of programmers and experts in the field of computer graphics [6].

In Europe and in the United States, electronic educational atlases are known, in which graphic images associated with certain localities, as well as with a brief description are presented [7]. A component of additional information provision was taken from these atlases. But, unlike the educational atlases of Europe and the USA, the product being offered contains a training program.

All of the abovementioned educational electronic atlases have only the educational function. Therefore, in comparison with the proposed GILS "TopoMaps" they have a common application without a narrow thematic specialization. In particular, all private examples for similar products are used in the school environment, but they are poorly adapted to the university program. GILS "TopoMaps" is aimed at the secondary and higher education.

\section{SUMMARY}

GIS, as one of the types of cartographic learning tools, is considered as a multifunctional and a complex one, they perform the functions of visualization, ensuring the operational activity of students: educating, developing, informational and propagandizing. A gradual and a continuous complication of tasks during the mastering of the basic methods of work with GIS, 
will lead to the increase in the interest of a studied object, as well as will stimulate a student to an independent creative approach for further problem solution.

GIS technologies provide users the ability to visualize source, derivative or summary data and processing results in thematic geographic maps. With the presence of GIS and geographic information, a learner will be able to receive answers to the questions about the location of objects, their interaction, to learn to explain natural phenomena, to use the knowledge gained in practical activities at the formulation of complex questions. Also, the school GIS allows you to solve the tasks faced by history, physics, ecology, OBZH, informatics and a number of others. This happens due to the fact that the school GIS allows you to look at a digital map not only as a source of educational information, but also as a spatial model. At that the model described by the formalized language is the language of conventional signs.

The study of school experience in Tatarstan makes it possible to talk about the use of school GIS in a comprehensive school during the development of meta-subjective universal educational activities, not only in educational, but also in design and research activities. A special attention is paid to the last one by CE FSES during the organization of the educational process. The implementation of the program will significantly expand the use of GIS in the teaching of geography at the schools of the Republic of Tatarstan.

\section{ACKNOWLEDGEMENTS}

The work is performed according to the Russian Government Program of Competitive Growth of Kazan Federal University.

\section{REFERENCES}

1. Gabdrakhmanov N.K., Rozhko M.V. The trends in the development of geographical information systems of tourist orientation // International Scientific and Research Journal. 2013. No. 9-3 (16). pp. 54-55.

2. Gabdrakhmanov N.K., Rubtsov V.A. The development of web-cartography on the example of the medical-demographic geo-information system development for the Republic of Tatarstan // Environmental consulting. 2011. № 1. pp. 26-33.

3. State educational standard of higher professional education on the specialty "032500 Geography". - M., 2005 p. 20.

4. Kapustin V.G. Gis-technology as an innovative tool for the development of geographical education in Russia // Pedagogical Education in Russia, 2009, - Issue No. 3, pp. 68-76 
5. O.A. Kreider. Information environment for the use of GIS technologies // Geoinformatics, 2005, - №4, pp. 49-52

6. Novenko D.V. The use of geoinformation technologies in school geographic education // Geography at school, 2007, -№7, pp. 36-41

7. S.K.Gubeeva. Geography information systems and teaching and learning geography in the republic of Tatarstan/S.K.Gubeeva, R.A.Ulengov, I.A.Urazmetov//SGEM Social Sciences Conference,-2016,-Vol.1,Book1,-pp,779-785.

8. FSES: basic general education. URL: http://standart.edu.ru

9. Finarov D.P. GIS: selection of content and the methods for their study within the school course of the Geography of Russia // Geography at school, 2005, - №5, pp. 56-58

10. Tim T. Favier, Joop A. van der Schee. Exploring the characteristics of an optimal design for inquiry-based geography education with Geographic Information Systems// Journal «Computers \& Education» 58. - 2012 - pp. 666-677. Amsterdam, The Netherlands

11. Mustafa G. Korucu. GIS and types of GIS education programs// Procedia - Social and Behavioral Sciences 46. - 2012 - pp. 209 - 215. Nicosia, North Cyprus

12. Penny Van Bergen, Soon Singh Bikar Singh, Grant Kleeman. Opportunities To Implement GIS In Teaching And Learning Geography: A Survey Among Smart Schools In Sabah, Malaysia// Procedia - Social and Behavioral Sciences 69. - 2012 - pp. 884 - 889. Sydney, Australia

\section{How to cite this article:}

Ulengov R A, Gabdrakhmanov N K. Problems of geoinformation system development and introduction in geographical education J. Fundam. Appl. Sci., 2017, 9(2S), 990-997. 